\title{
An Exploration on the Process of Brand Identity Building in the Context of Malaysian Cafe
}

\author{
SABRINA MOHD RASHID \\ Universiti Utara Malaysia \\ DAVID COHEN \\ University of Canterbury, New Zealand \\ KAMAL GHOSE \\ Lincoln University, Australia
}

\begin{abstract}
Identity is vital when communication takes place. Thus, building a strong brand identity has become a prime marketing concern for many business owners. In previous years, the focus was on the communication between the organisation and the customers. This study extended previous research by focusing on the business concept and identity and their approach of communicating themselves (brand) to the public, a step further in safeguarding a place in the enormous business industry. A qualitative approach with semi-structured interviews ware used to explore the food and beverage industry, focusing on independent coffee shops. The interviews were carried out with five independent coffee shops in Kuala Lumpur, Malaysia. According to the finding of this research, there is a lacking in the investment on the execution of brand for these independent coffee shops. This research also initiates that the inclusion of (the owner's) roots, identity, and meaning of names are relevant when building an identity of a brand to have a distinctive business concept. This study contributed to our understanding of how brand identity was built and then connected it to the internal culture of the coffee shop. The findings suggested that the process of creating and building a brand identity was more complicated than just producing the visual imagery in order to build and communicate distinctively.
\end{abstract}

Keywords: Brand, brand identity, brand story, coffee shops, Malaysia.

\section{INTRODUCTION}

"The best brands are built on great stories."

- Ian Rowden

Chief Marketing Officer, Virgin Group

A story is a message being told to people. Storytelling has power in communicating and letting the audience reminisce what are shared. It can be descriptive, and able to create strong passionate bond and memories. We remember great stories. Great stories connect us to philosophies and beliefs. Great story facilitates and inspires people to share, and stimulates words of mouth.

Harley-Davidson is one of the world's enduring brands that has a great story behind it. "A Harley rider's love for his motorcycle has nothing to do with how fast it goes or how much it costs. It has to do purely and simply with the Harley story: when that accountant rides his 
Harley, he's unleashing himself from his family and work commitments and, even if only for three hours a week, becoming somebody he has never been and never will be except when he gets on his Harley" (Leventhal \& Papadatos, 2006). A Malaysian brand, Petroleum Nasional Berhad (PETRONAS) is also one of the leading brands known widely in the world. PETRONAS is known as the custodian for Malaysia's national oil and gas resources, delivering energy to meet society's growing needs.

A brand is like a species, or as been said in literatures as a deoxyribonucleic acid (DNA). At its core, a brand encompasses an extensive range of focus related to the growth, care and enhancement of the brand. The purpose of this paper is to accentuate the importance of having an identity in a brand. The practice of having an identity attached to a brand added its value and says what the brand wants to be. It is an incredibly valuable implementation if it starts at an early stage as a brand has a huge world on its own. Thus, the rationalization of brand management by marketing scholars (Aaker, 2012; Brochado, Vinhas da Silva, LaPlaca, Bruwer, \& Bruwer, 2015; Kapferer, 2012; Keller, 2013; Vanauken, 2002) is important in order to lessen misunderstandings about brand architecture. Therefore, the need to have and a common understanding of the term "brand" is critical in order to interpret the brand further.

The motivation for this study is due to the continuation rising of small business industry in Malaysia (Bashir, Aslam, Ibrahim, \& Kaur, 2017). There is a common absenteeism of a clearly defined approach taken by brands to penetrate emerging crowded markets with their names and concepts (Rashid, Ghose, \& Cohen, 2015).Thus, product and services business have grown significantly and the competition is high among similar businesses, this has a declining impact on their followers (Rahman \& Noor, 2014) which has called for a restructuring of brand process that has a stronger voice on its distinctive identity.

\section{Brand and its definition}

\section{LITERATURE REVIEW}

To define a brand is intricate. It needs a deliberate method in providing a meaning of brand (Blois, 2000). Thus, many efforts have been made to define the word. Barlow and Stewart (2004) give a very simple and clear definition of the brand as "a unique identity". According to the American Marketing Association (AMA) brand is a "name, term, sign, symbol, or design, or a combination of them, intended to identify the goods and services of one seller or group of sellers and to differentiate them from those of the competition" (Keller, 2013). Davis (2010) provides an updated brand definition by the AMA (Alexander, 1960):

A brand is a customer experience represented by a collection of images and ideas: often, it refers to a symbol such as a name, logo, slogan and design scheme. Brand recognition and other reactions are created by the accumulation of experiences with the specific product or service, both directly relating to its use, and through the influence of advertising, design and media commentary.

An additional definition to brand is: A brand often includes and explicit logo, fonts, colour, schemes, symbols, sound, which may be developed to represent implicit values, ideas, and even personality. 
The influence of media and media commentary are included in the updated definition provided by the AMA. This is necessary as consumers are involved in various experiences with products or services. The term brand differentiation is replaced with brand recognition. To leave out an important component in a definition such as brand differentiation could defeat the essence of the brand. After all, brand recognition commenced with the presence of brand differentiation. Specifically, brand is accepted through its distinguishing identity in making it dissimilar from other brands; therefore, brand differentiation is an important component that should remain in the definition.

This paper has the intentions to provide the distinctiveness and creativity that a brand should have in building up its identity. In order for a brand to be different, one of the essentials in making a product or service appeal to consumers is to adhere to one root. To be different is to be rare, to be creative, which may indicate a positive or a negative reaction among consumers (i.e. trying new product, anxiety, fear). A brand is expected to echo more with consumers if it has an identification mark, symbol, word (s) or mixture of those to distinguish its product or service from other companies, thereby creating a unique identity (Godin, 2009; Imber \& Toffler, 2008; Jevons, 2005; Kotler, 1997)

One of the first definitions of a brand comes from Gardner and Levy (1955), as cited in Davis (2007). They viewed brand as a symbol with deep interpretation and stories to tell instead of just to differentiate a brand from another brand:

... a brand is more than a label employed to differentiate among manufacturers of a product. It is a complex symbol that represents a variety of ideas and attributes. It tells the consumer many things not only by the way it sounds (and its literal meaning if it has one) but, more importantly, via the body of associations it has built up and acquired as a public object over a period of time.

De Chernatony and Riley (1998) brought a different aspect to defining brand by describing the branding development by combining eight elements they believed were significant in branding; functional capability, symbolic feature, service, name, ownership, notation, legal protection, reduction of risk and strategic direction.

Brands start life with distinctive names, possibly endorsed by the corporate reputation or sign of ownership. The brand's functional capabilities become recognized and, to build a relationship with consumers, the service component becomes important. Legal protection is used to deter competitive infringement, but the symbolic feature gives the brand a personality, making it more difficult to copy. As consumer confidence increases, through skilful presentation as a risk reducer, the brand becomes associated with unique added values and becomes an effective shorthand notation representing a few high quality pieces of information facilitating rapid consumer choice. 
The process, as described by de Chernatony and Riley (1998), summarizes what brand is all about; which is to be dissimilar, to have proprietorship rights and to gain customers' assurance in their product or service. Wagner and Peters (2009) focus on the protection of the brand, they believe that "the most important function of a brand is to protect the trademark owners from imitation." This is because, a brand is an asset to the organization it belongs to, hence, the need to protect the brand from illegal activities such as imitation, copying and use without copyright. Preventing and protecting the brand from being counterfeited and customers from being deceived is a complex task, but need to be done. Providing brand knowledge and brand awareness to customers will help them in making a choice without being manipulated. This is significant because the first impression and interaction that a customer has with a product or service will largely determine their perceptions, and grab the creative attributes of what the brand has to offer.

The customers' perceptions develop from their experience and this happens in every interaction with the brand (Hogan, Almquist \& Glynn, 2005). Godin (2009) agrees with Hogan, et al (2005) that brand relates to the customer experience. According to Godin:

\begin{abstract}
A brand is the set of expectations, memories, stories and relationships that, taken together, account for a consumer's decision to choose one product or service over another. If the consumer (whether it's a business, a buyer, a voter or a donor) doesn't pay a premium, make a selection or spread the word, then no brand value exists for that consumer (Godin, 2009).
\end{abstract}

Besides playing an important role in engaging the consumer market, a brand also plays a large part in the product and financial markets (Keller \& Lehmann, 2006). Therefore, a brand is more than just a product or service because its unique dimensions that are designed to satisfy the same needs (Keller, 2013). The brand of a product or service should be identifiable by its own unique attributes that distinguish it from other brands. Apple, Google, Honda, the All Blacks, Adidas, and Samsung are among international brands that are known widely. People from most countries will know what IKEA is about, what to anticipate from a Subway and how $L E G O$ functions. These are among the strong brands that have their own identity and are well-known of its unique and creative dimensions among the consumers and the general public.

In summary, the definition of the brand can be concluded as, "a brand will be understood as a unique identity, given specifically to a product or a service, which is communicated in the form of a term, symbol, design, sound, experience or a combination of these, to consumers. When a brand communicates to the customers it sends a promise of what will be delivered or experienced. Like a person, a brand must have an identity and it should be clearly revealed" (Rashid, 2012). This definition has provided a new dimension on the brand plethora with the addition on the importance of having its own creative identity.

\title{
Constructing Brand Identity
}

The concept of brand identity has been researched in some depth (Christmann, Alexander \& Wood, 2015; De Chernatony, 1999; Keller, 2001; Lawrence \& Kaufmann, 2015; Lory \& McCalman, 2002; Nandan, 2005; Phillips, McQuarrie \& Griffin, 2014). This multidisciplinary domain has led to a variety of descriptions and conceptual frameworks that reflect this 
relevant concept. "Brand identity includes a set of features and dimensions that determine the brand's way of being, thinking and behaving. It is, therefore, a key concept in brand management, as brand identity defines not only the purpose and meaning of the brand, but also the directions to follow" (Buil, Catalán, \& Martínez, 2016). In recent research, it has been said that the key design in a brand appearance (on the product) should retain as the fundamental design for continual development (Ondra, Škaroupka, \& Rajlich, 2017).

Kapferer (2012) argues that having an identity indicates "being your true self, driven by a personal goal that is both different from others' and resistant to change". Konecnik and Go (2008) give new insights into the concept of brand identity. They assert that brand identity states what the brand aspires to be. A successful brand:

- Constitutes a set of associations that the brand strategist seeks to create and maintain.

- Represents a vision of how a particular brand should be perceived by its target audience.

- Establishes a relationship between a particular brand and its clientele by generating a value proposition potentially either involving benefits or providing credibility, which endorses the brand in question.

In accepting Koneckik and Go's insights, it appears likely that a better understanding of the brand identity concept will be communicated to potential customers. The brand of a product or service needs to have its own unique identity that makes it stand out and be recognizable by its customers. Kapferer (2012) believes that a brand with identity is more likely to survive in the fast-growing marketing industry since it can connect better with customers. As can be seen, the coffee shop industry is an emerging market currently, thus, it is important to have a unique identity and recognizable.

The process of creating and maintaining a brand needs to be systematically planned (Lee et al., 2017). Brand identities are built using two elements; specialization and authority (Kitchen \& Schultz, 2003). Specialization is what the organisation does best and what makes it different from other organisations in moulding the brand and its identity. The second element, authority, is about the basis of the identity and encompasses dimensions such as quality, leadership and trustworthiness among individuals in the organisation. It is essential for a brand to have both virtues (specialization and authority) to grow and compete with existing brands. This research focuses on the concept of identity creation, specialisation and authority among the essential elements that are needed to distinguish an organisation. Integrating these two elements together is likely to provide a complete guide to building a unique coffee shop.

More actions for building a brand have been suggested by Aaker and Joachimsthaler (2000) who claim that "brand identity needs to resonate with customers, differentiate the brand from competitors and represent what the organisation can and will do over time." The researchers agree with Aaker and Joachimsthaler that it is important to identify what are the customers' desires and to identify what competitors are doing.

"A set of brand associations enable a brand to develop a rich and clear brand identity" (Ghodeswar, 2008). Brand building relates to brand identity in many ways. For example, a new brand in the market depends mostly on identity creation. Brand identity is strongly 
related to consumer perception and visible elements (including brand names, logos / symbols, typeface, colours, shapes and product benefit descriptions used in advertising, package, product identification, publications, letterheads and websites), either real or imagined (Zaichkowsky, 2010). Therefore, creating a distinctive brand is necessary to get customers' attention.

The article, "Who owns the brand?" (Schultz, 2002) suggests that building a brand should start internally before it is released to the public. The members of the organisation should be provided with clear brand knowledge in order to communicate the brand to the public. Vallaster and de Chernatony (2005) agree with Schultz. "The process of internal brand building advances when a clear brand vision creates tension between the actual and ideal work setting, forcing people to work together to reduce this gap".

Ambler (2002), however, advocates a different starting point in the building of a brand. Many scholars (Burmann \& Zeplin, 2005; Schultz, 2002) suggest that brand building should start within the organisation, but Ambler suggests that it has to be formed from the consumers' expectations in order to meet their demands. Both views are right based on the context of the situation. For example, as shown in the brand identity prism model (Kapferer, 2012) a brand can be simultaneously constructed internally (within organisation) and externally (by consumers), thus it has a sender (the organisation) and a receiver (the customers) to demonstrate the process of building a brand. This process could be a time consuming process (Ghodeswar, 2008) as it involves a lot of internal and external processes. As does Ghodeswar, Schultz (2002), who describe the process of branding as something that does not happen overnight, but which needs to be nurtured over time in order to encourage active communication:

Branding isn't rocket science, but it isn't something done on the spur of the moment or by a committee in one afternoon. Most of all it isn't done by communication alone. Brands are built by customer and stakeholder experience. Communication is just one of those experiences.

Empirical research on brand identity have provide gaps (Coleman, de Chernatony, \& Christodoulides, 2015) and calls for the need to carry out this research and explore in depth, especially in Malaysia. Lack of brand identity research related in Malaysia has called for this study.

\section{RESEARCH CONTEXT}

There are various types of coffee shops, each with its own unique traits. For this study, independent coffee shops were explored. Starbucks is the most obvious example of a (franchise) coffee shop, although, there are other independent coffee shops with their own business format. This research aims to understand how the owners and creators of these coffee shops operate their businesses and how they create and imbue them with special character.

Coffee shops, or cafés (Kiefer, 2002), initially served tea, hot chocolate and coffee and, later, added fruits confits, chocolate, ice cream and sorbets. These are among the common expectations of customers about what is offered in a coffee shop. The concept of the coffee shop was introduced in about 1685 and had a considerable influence on coffee imports by 1692 (Kiefer, 2002), earlier than the emergence of the restaurant. A clear explanation of 
cafés and coffee shops is given in Goetz, (1990), "A café is a small eating and drinking establishment, historically a coffee house, usually featuring a limited menu that seldom includes liquor". Coffee shops have become an obligation, a trending that is not to miss, an outlet that unite diverse crowd extending from students, executives, entrepreneurs, seniors, and public (Susanty \& Kenny, 2015).

\section{RESEARCH METHODOLOGY}

The focus of this research is to emphasise on the significance of having an identity build on a brand and its approach in communicating it. The questions posed in this study is to accentuate on the importance of having a story of a brand. In order to understand and address the question, the researchers unfold the findings by using qualitative approach and interviews with five participants. The qualitative approach may unfold the data in depth. Besides, in depth interviews, continuous observations in the outlet were also being carried out during this procedure. This study has been conducted in Kuala Lumpur, Malaysia. Malaysia is a budding nest for coffee going lovers. All over the Malaysia, café business has been growing with creative and fresh concepts.

Participants for this study are the owners of independent coffee shop (ICS) outlet. The interviews were transcribed and analysed by using a thematic analysis approach. The analysis provides an interpretation of the data and what has been discovered from this study. Besides, in depth interviews, continuous observations in the outlet were also being carried out during this process.

Thematic content analysis is a descriptive presentation of qualitative data that is used in this research. This research used this approach in interpreting and evaluating the interview transcriptions and coding to ensure it represents the context of this research. The purpose of categorising content into themes was also to present the different expressions of the data. Thematic content analysis categorizes common thoughts provided in the data analysed. The researchers could see the emerging thematic ideas through this process. The reliability and validity of the thematic analysis process were increased through the quotes from the participants and this conferred accuracy and intricacy of the data.

\section{The Art of Brand Name}

\section{FINDINGS}

Creating or acquiring a brand name was among the first steps that needed to be taken when creating a brand identity. In this study, the term "brand" was used by the organisations to describe and communicate who they were and the name given to their coffee shop. Independent Coffee Shop (ICS) owners in Malaysia have a fair understanding on this. This is demonstrated by ICS 1, he explained in depth on the reason of choosing the name for the coffee shop:

Name of the café was chosen with intention, the coffee shop is to attract the young generation. Something different and attractive. [Which is the] meaning of the name is about facial expression. It is very rare thing to have a meaning of the shop which comes out to me a facial expression (ICS 1). 

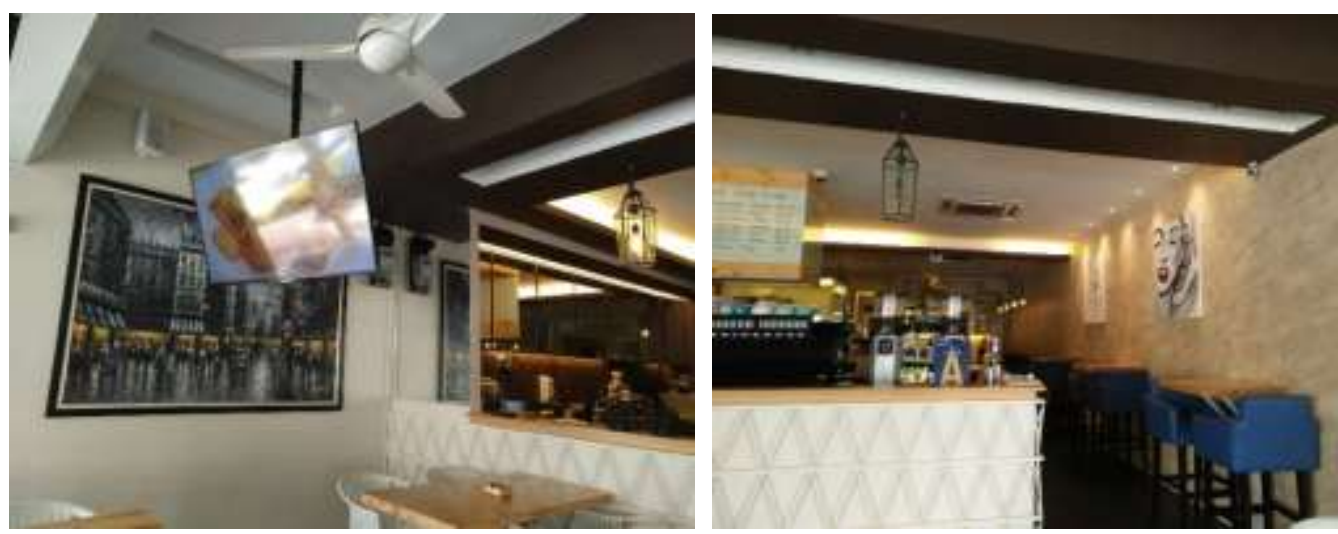

Figure 1: ICS 1 and its contemporary look.

ICS1 focused more on their perception of what the customer may like. Most ICS participants did not invest time or money on the branding exercise. Most of the names chosen for their businesses were chosen spontaneously, without much thought.

Data analysis from previous research revealed that the participants from the franchise coffee shops (FCSs) gave considerable thought to what it meant to have a good brand, since they were well trained by the franchisor prior to joining the organisation (Rashid, 2012). FCS participants found that having a well-known name helped boost customer traffic. For some of the ICS owners, the name of the shop was significant and may have influence on getting more customers or to increase trade. The participant from the ICS 2 used a word from a foreign language that translate as an eye opener, which is also the concept that they want to instil in this café. They also bring in parts of their furniture from other countries using recycled materials to provide a distinctive look and feel.
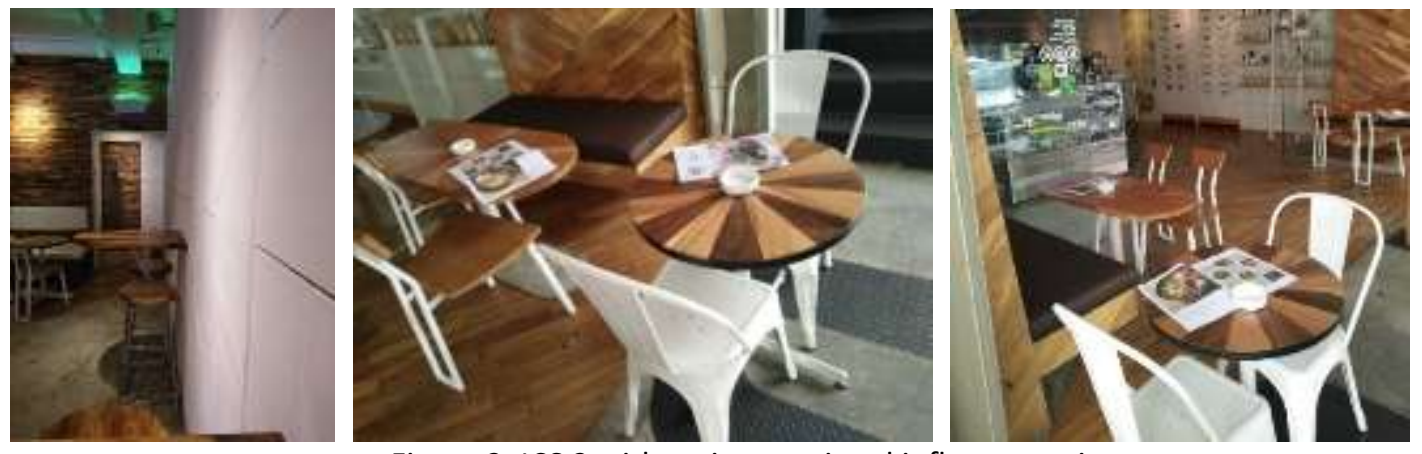

Figure 2: ICS 2 with an international influence to it.

This café also made an attempt to translate their concept to their customers to have an eye opener.

“... we are into hipster style. To attract youngster as you can see our design consist of lots of power points where youngsters can relax here doing their homework or assignments." 
ICS 3, has been very authentic and interesting to choose a famous ingredient in their cake recipe as their café name. ICS 3 explained that they choose that particular ingredient as their café name because of its importance and functions to support the cake and its texture. ICS 3 has put a very deep thought into this with a strong justification. This mother-daughter joint café has a very pleasant concept for their customer, a very family oriented café that is suitable for get together and functions, with more than ten (10) year experiences in this industry.

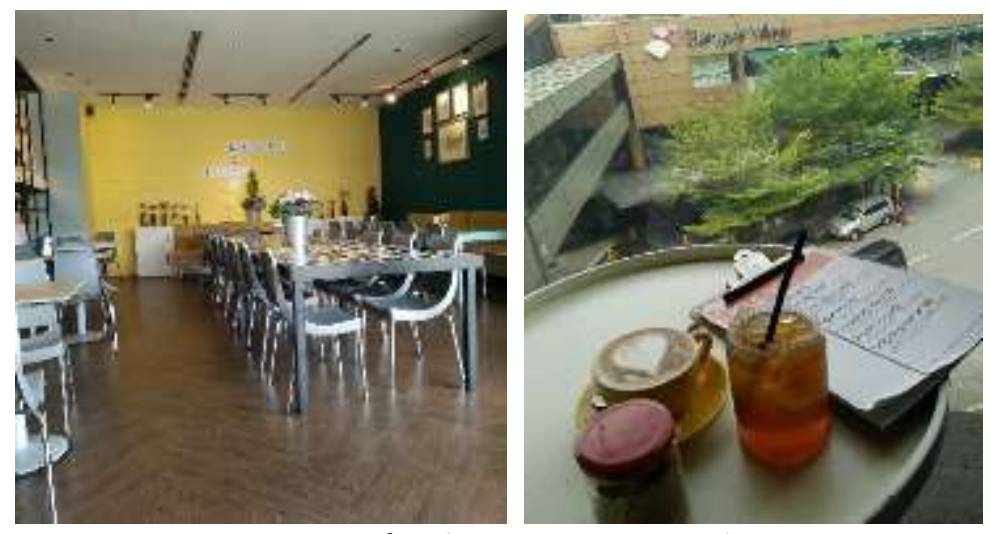

Figure 3: ICS 3 family setting space, and its view.

Having the right brand name also may offer easy brand recognition and it may also reduce the branding route required, especially in creating an identity for the outlet. The brand name innumerable purposes "identified as connotation, denotation, linking and branded entity constancy, are ongoing important providers of brand equity to some consumers for established branded entities" (Round, Round, Roper, \& Roper, 2017). The right brand name was generally easy to relate to, descriptive, and had a strong meaning behind it. It also helped create a brand personality. It was possible to create a memorable name that would noticeably increase response rates for current and potential customers, such as ICS 1. They have utilised a word that will attract youngsters and crowds that loves contemporary concept.

ICS 1 brand name was short, simple and easy to remember, however, he did not have a strong basis for the name which might cause difficulties in creating a strong brand identity for his shop. Not having the appropriate brand name could result in customer confusion.

\section{The Construction of the Concept}

Lawler (2008) stated that, although forming an identity could be as simple as looking at the core roots of the business, it can be a complex process of identification. Identification has a strong link with the concept exposed in an outlet. ICS 4 has a different concept completely. They have combined the two concepts together, that is café and hobby. The café name demonstrates the concept. The owner of ICS 4 believes that a café needs to have an extension to it, such as they have a café and also a place to play games perhaps. For ICS 4 , besides a café, they also have class and a hands-on place to learn sewing. These ' 2 in 1 ' concept is a budding concept in the area (of place) it seems. 
Nearby ICS 4, is another outlet, ICS 5 that has the same concept café. ICS 5 is a café combining food and beverage with cats. They also have a play area for customers to have an enjoyable time with the cats. The café name insinuated this clearly. ICS 4 and ICS 5 have a very clear concept with a focused customer group.
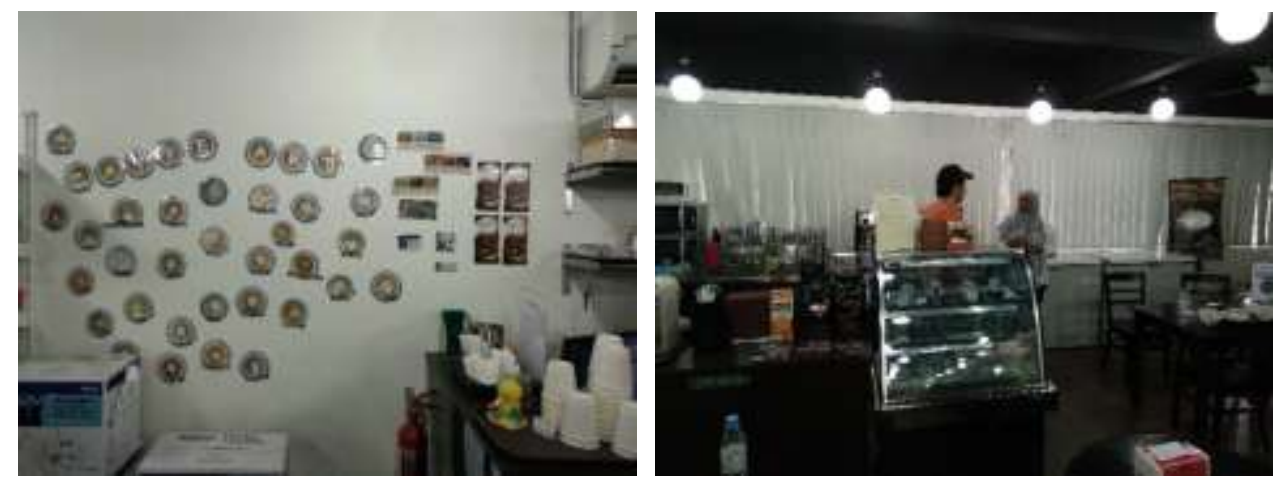

Figure 4: ICS 4 and Part of Its Café and Hobby Space.
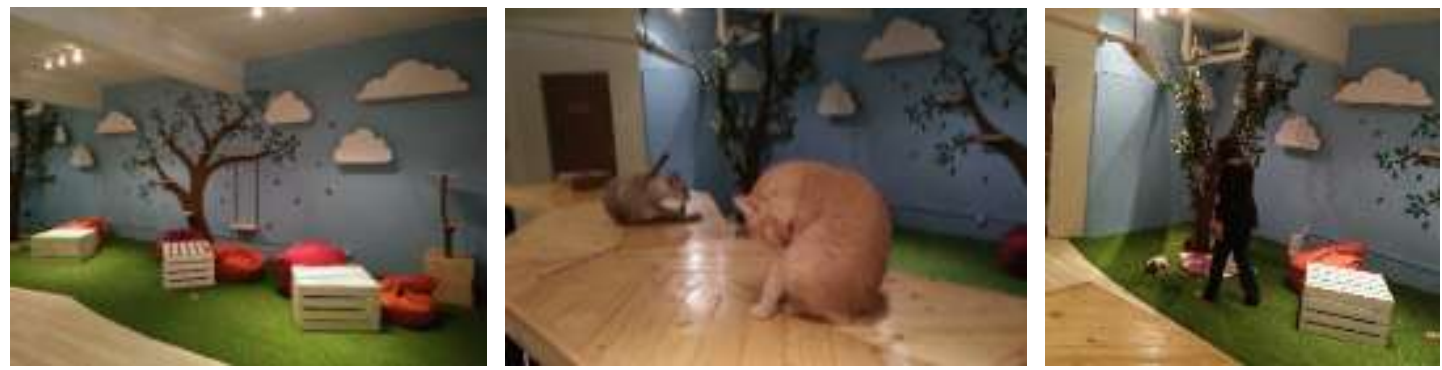

Figure 5: ICS 5 bringing in a fresh concept of a hobby café.

The findings of the present research indicated that even looking at the roots will not do justice in creating an identity for an organisation, it was beyond the roots. To create a clear brand identity, the creator of the brand needed obligate a concept and visualize how the brand would fit into the competitive industry and able to communicate commendably (Rashid \& Ghose, 2015).

\section{Delivering an Inclusive Brand Identity}

The process of identification needed to be put together cautiously in order to produce a comprehensive brand concept. To achieve an inclusive identification, it was necessary for the ICS put more exertion into choosing a brand name that was consistent with the concept of the coffee shop or organisation. For example, ICS 2, related his roots by using his mother tongue language as the name of the café.

The consistency of practise in relating his roots to the name of one shop and also into the concept of the shop, has minimised any confusion arising in the brand recognition process. This finding was in agreement with Klink and Wu (2017) who asserted that there were two reasons why the brand name was important for brand building. First, a brand name provided a consistent and continuing source of differentiation and can be used for brand extension. Secondly, brand names provided considerable indication about the feelings and influence of the buying decision for potential customers (Moriuchi, Moriuchi, 
Jackson \& Jackson, 2017). ICS 3 has related its brand name to their best product that is their desert range and ICS 4and ICS 5 has demonstrated that they are just not a café, but an extension of one. It was apparent that having a distinctive and consistent brand name played a major role in the identification process of some of the organisations.

The findings of this study also indicated that a unique brand name ensured that an outlet stood out from the crowd. It was even better if the name could act as a trigger for consumers, with the brand name representing the meaning of the outlet. For example, if the name of the outlet was Pronto, it may suggest to the public that this outlet has some association with Italian concepts (such as the menu or the interior decoration). The association of the outlet name with its Italian essence generated national associations and perceptions.

A brand name was part of the brand elements which also included logos, symbols, packaging and slogans (Keller \& Lehmann, 2006). These elements played an important role in distinguishing the brand and the concept. Unlike ICS, most of the FCS participants placed their brand elements almost everywhere, on their coffee cups, plates, serviettes, sugar packaging and, also, on their walls, as a way to strengthen the brand and its concept. FCS maximise their use of brand elements to provide a solid foundation for building their identity. The brand elements were among the main components that standardized the appearance of the franchises. This was an advantage to FCS owners because the franchisors have a formatted business and marketing plan to assist them in establishing and supporting their brand name (Rashid, 2012) .

None of the ICS participants have practiced this. Most of them go as far as having their brand on the serviette only. The lack of brand element use was apparent in the ICS operations. This may have resulted from a lack of funds for the purpose of designing logos, providing uniform designs for cups and saucers, and other brand elements. Another possible reason for paying less attention to brand elements might have been that the ICS owners were not aware of their impact of these on their customers. They will have an effect, mostly on the engagement of the customers with the identification of the ICS; hence, additional attention should be given when supporting the brand with these presentations of the brand name and concept.

\section{DISCUSSION}

From the data collected, it is found that, there is a lack of brand identity element implementation in the ICS operations. This may have resulted from a lack of funds for the purpose of designing logos, providing uniform designs for cups and saucers, and other brand related elements. Another possible reason for paying less attention to the brand strong elements might have been that the ICS owners were not aware of their impact of these on their customers. The consequence will be highly weighed on the engagement of the customers with the identification of the ICS which is the name; hence, further attention should be given when associating the brand with these presentations to enhance active communication. This study found that creating a brand identity has identifiable and continuous processes in order to attain a distinctiveness and sturdiness in shaping the brand identity to enhance its relationship with customers. On a broader spectrum, a brand reflects the owner's identity and vision, thus, it is significant of the owners to retain the roots of the creator identity into the brand. 
Developing an appropriate identity through having a distinctive identification creation process, and introducing a fresh concept were the recommendations from this research towards having a transformed concept for coffee shop brand identity in Malaysia.

The findings from this research is very relevant to the current situation which coffee consumption is increasing worldwide (Carvalho, Paiva \& Vieira, 2015; Ferreira, 2017; Gonsalves \& Dias, 2015; Pleshko \& Heiens, 2015) and drinking coffee has becoming a lifestyle (Kim, Kim, Lee \& Lee, 2017). Coffee shops or cafes, or any service industries are encouraged to be more competitive and to be distinctive in renewing their concept especially their distinctive identity. The findings of this research may also be utilized and applied for future research in other areas of service industry such as saloons, banks, or hospitals.

\section{CONCLUSION}

The researchers found that, most of the ICS owners are convinced with the concept and identity of their coffee shop. Instead of having a monophonic concept of coffee shop, which is only to serve food and beverage, they also, have an alternative method of presenting their coffee shop. The alternate coffee shop offers a wider range of events to do while customers are dining in. This alternate concept is relatively important in order to entice and engage customers from diverse interest to get together in one coffee session. This can be seen in coffee shops such as ICS 5, some customers go to ICS 5 because of their love for coffee, and they can also bring their cat lovers friends to come and share a good quality time together.

More studies are needed with regard to understanding brand identity and the role it played in setting a culture (Chelliah, Jaganathan, \& Chelliah, 2017) in motion and the eventual success or failure of a business. It is the researchers' hope that the insights from this study will help to guide future researchers and organisational professionals, not forgetting practitioners who strive to create a distinctive concept in order to have their identity being heard strong. The alternate concept should be an emphasis in order to be a competitive player in the industry.

\section{ACKNOWLEDGMENT}

This research is part of the Confirmation Grant, from College of Arts and Sciences, Universiti Utara Malaysia (S/O Code: 13612). 


\section{BIODATA}

Sabrina Mohd Rashid, PhD, is a Senior Lecturer in Department of Multimedia Technology, School of Multimedia Technology and Communication, UUM. She obtained her PhD in Marketing from Lincoln University, New Zealand. Her MSc is in Corporate Communication from Universiti Putra Malaysia, and, her BSc in Media Innovation is from Multimedia University. Her research area focus is in brand identity and internal culture. Email: sabrina@uum.edu.my

David Cohen, PhD, is an Associate Professor in Marketing at Lincoln University, New Zealand. David's research areas are in brand, consumer behavior, and winery. Email: David.Cohen@lincoln.ac.nz

Kamal Ghose, PhD, is currently a Lecturer, Academic Director, and Brand Strategy Consultant in Kaplan Business School, Melbourne, Australia. Kamal's research area is in brand strategy. Email: K.Ghose@lincoln.ac.nz 


\section{REFERENCES}

Aaker, D. A. (2012). Building strong brands. New York: Simon and Schuster.

Aaker, D. A., \& Joachimsthaler, E. (2000). Brand leadership: The next level of the brand revolution. New York.

Alexander, R. S. (1960). Marketing definitions: A glossary of marketing terms. Chicago: American Marketing Association.

Ambler, T. (2002). Comment: Customer lifetime values-credible, or utterly incredible? Journal of Targeting, Measurement and Analysis for Marketing, 10(3), 201-202.

Barlow, J., \& Stewart, P. (2004). Branded customer service: The new competitive edge. Berrett-Koehler Publishers.

Bashir, S., Aslam, M., Ibrahim, F., \& Kaur, K. (2017). Consumer's perceived communicational risks in predicting internet-based shopping intention. Jurnal Komunikasi - Malaysian Journal of Communication, 33(1).

Blois, K. (2000). The Oxford textbook of marketing. Oxford University Press.

Brochado, A. O., Vinhas da Silva, R., LaPlaca, P., Bruwer, J., \& Bruwer, J. (2015). Assessing brand personality associations of top-of-mind wine brands. International Journal of Wine Business Research, 27(2).

Buil, I., Catalán, S., \& Martínez, E. (2016). The importance of corporate brand identity in business management: An application to the UK banking sector. BRQ Business Research Quarterly, 19(1), 3-12.

Burmann, C., \& Zeplin, S. (2005). Building brand commitment: A behavioural approach to internal brand management. The Journal of Brand Management, 12(4), 279-300.

Carvalho, J. M., Paiva, E. L., \& Vieira, L. M. (2015). Quality attributes of a high specification product: Evidences from the speciality coffee business. British Food Journal, 118(1), 132-149.

Chelliah, T. D., Jaganathan, M., \& Chelliah, M. K. (2017). Adoption of corporate social responsibility: Empirical evidence from Malaysian SMEs. Jurnal Komunikasi, Malaysian Journal of Communication, 33(4).

Christmann, H., Alexander, A., \& Wood, S. (2015). Exploring brand identity and entrepreneurship as drivers of small specialist retailer internationalisation: A German case study. The International Review of Retail, Distribution and Consumer Research, 117.

Coleman, D. A., de Chernatony, L., \& Christodoulides, G. (2015). B2B service brand identity and brand performance: An empirical investigation in the UK's B2B IT services sector. European Journal of Marketing, 49(7/8), 1139-1162.

Davis, J. A. (2010). Competitive success, how branding adds value. John Wiley \& Sons.

Davis, J. C. (2007). A conceptual view of branding for services. Innovative Marketing, 3(1), 7 14.

De Chernatony, L. (1999). Brand management through narrowing the gap between brand identity and brand reputation. Journal of Marketing Management, 15(1-3), 157-179.

De Chernatony, L., \& Dall'Olmo Riley, F. (1998). Modelling the components of the brand. European Journal of Marketing, 32(11/12), 1074-1090.

Ferreira, J. (2017). Café nation? Exploring the growth of the UK café industry. Area, 49(1), 69-76.

Ghodeswar, B. M. (2008). Building brand identity in competitive markets: a conceptual model. Journal of Product \& Brand Management, 17(1), 4-12. 
Godin, S. (2009). Purple Cow, new edition: Transform your business by being remarkable-includes new bonus chapter. Penguin.

Goetz, P. W. (1990). The new encyclopaedia Britannica (Vol. 20). Chicago: Encycplopaedia Britannica. Inc.

Gonsalves, S. S., \& Dias, F. (2015). A study on consumer attitude towards café coffee day. Reflections-Journal of Management, 5.

Hogan, S., Almquist, E., \& Glynn, S. E. (2005). Brand-building: Finding the touchpoints that count. Journal of Business Strategy, 26(2), 11-18.

Imber, J., \& Toffler, B.-A. (2008). Dictionary of marketing terms. Barron's snippet.

Jevons, C. (2005). Names, brands, branding: Beyond the signs, symbols, products and services. Journal of Product \& Brand Management, 14(2), 117-118.

Kapferer, J.-N. (2012). The new strategic brand management: Advanced insights and strategic thinking. London: Kogan page publishers.

Keller, K. (2013). Strategic brand management: Global edition. Pearson Higher Ed.

Keller, K. L. (2001). Building customer-based brand equity: A blueprint for creating strong brands. Marketing Science Institute Cambridge, MA.

Keller, \& Lehmann, D. R. (2006). Brands and branding: Research findings and future priorities. Marketing Science, 25(6), 740-759.

Kiefer, N. M. (2002). Economics and the origin of the restaurant. The Cornell Hotel and Restaurant Administration Quarterly, 43(4), 58-64.

Kim, S.-H., Kim, S.-H., Lee, S., \& Lee, S. (2017). Promoting customers' involvement with service brands: Evidence from coffee shop customers. Journal of Services Marketing, 31(7), 733-744.

Kitchen, P. J., \& Schultz, D. E. (2003). Integrated corporate and product brand communication (1). Journal of Competitiveness Studies, 11(1), 66.

Klink, R. R., \& Wu, L. (2017). Creating ethical brands: The role of brand name on consumer perceived ethicality. Marketing Letters, 1-12.

Konecnik, M., \& Go, F. (2008). Tourism destination brand identity: The case of Slovenia. Journal of Brand Management, 15(3), 177-189.

Kotler, P. (1997). Marketing management-analysis, planning, implementation, and control. New Jersey: Prentice Hall.

Lawrence, B., \& Kaufmann, P. J. (2015). Identity tensions in business-based brand relationships. Strong Brands, Strong Relationships, 310.

Lee, W. J., Lee, W. J., O'Cass, A., O'Cass, A., Sok, P., \& Sok, P. (2017). Unpacking brand management superiority: Examining the interplay of brand management capability, brand orientation and formalisation. European Journal of Marketing, 51(1), 177-199.

Leventhal, R. C., \& Papadatos, C. (2006). The art of storytelling: how loyalty marketers can build emotional connections to their brands. Journal of Consumer Marketing, 23(7), 382-384.

Lory, M., \& McCalman, J. (2002). Management consultancies as brands: Can David learn from Goliath?. The Journal of Brand Management, 9(6), 412-429.

Moriuchi, E., Moriuchi, E., Jackson, P. R., \& Jackson, P. R. (2017). Role of brand names and product types on bicultural consumers' purchase intentions. Journal of Consumer Marketing, 34(1), 53-65. 
Nandan, S. (2005). An exploration of the brand identity-brand image linkage: A communications perspective. The Journal of Brand Management, 12(4), 264-278.

Ondra, M., Škaroupka, D., \& Rajlich, J. (2017). Innovating product appearance within brand identity. International Journal of Innovation Science, 9(2).

Phillips, B. J., McQuarrie, E. F., \& Griffin, W. G. (2014). How visual brand identity shapes consumer response. Psychology \& Marketing, 31(3), 225-236.

Pleshko, L. P., \& Heiens, R. A. (2015). An investigation of chronological versus cognitive age impact in the kuwait coffee shop market. Organizations and Markets in Emerging Economies, 6(1).

Rahman, N. A. A., \& Noor, S. M. (2014). The role of brand self-relevance in developing brand loyalty: A study on the brand loyalty for Honda. Jurnal Komunikasi, Malaysian Journal of Communication, 30(2).

Rashid, S., \& Ghose, K. (2015). Organisational culture and the creation of brand identity: Retail food branding in new markets. Marketing Intelligence \& Planning, 33(1), 2-19. http://doi.org/10.1108/MIP-10-2013-003

Rashid, S. M. (2012). An Exploration of the process of brand identity building and internal organisational culture. Lincoln University.

Rashid, S. M., Ghose, K., \& Cohen, D. A. (2015). Brand identity: Introducing renewed concept for coffee shops. PEOPLE: International Journal of Social Sciences, 1(1).

Round, G., Round, G., Roper, S., \& Roper, S. (2017). When and why does the name of the brand still matter? Developing the temporal dimension of brand name equity theory. European Journal of Marketing, 51(11/12), 2118-2137.

Schultz, M. (2002). Who owns the brand?. Marketing Management, 11(5), 8.

Susanty, A., \& Kenny, E. (2015). The relationship between brand equity, customer satisfaction, and brand loyalty on coffee shop: Study of Excelso and Starbucks. ASEAN Marketing Journal, 14-27.

Vallaster, C., \& De Chernatony, L. (2005). Internationalisation of services brands: The role of leadership during the internal brand building process. Journal of Marketing Management, 21(1-2), 181-203.

Vanauken, B. (2002). The brand management checklist. London.

Wagner, O., \& Peters, M. (2009). Can association methods reveal the effects of internal branding on tourism destination stakeholders?. Journal of Place Management and Development, 2(1), 52-69.

Zaichkowsky, J. L. (2010). Strategies for distinctive brands. Journal of Brand Management, 17(8), 548-560. 